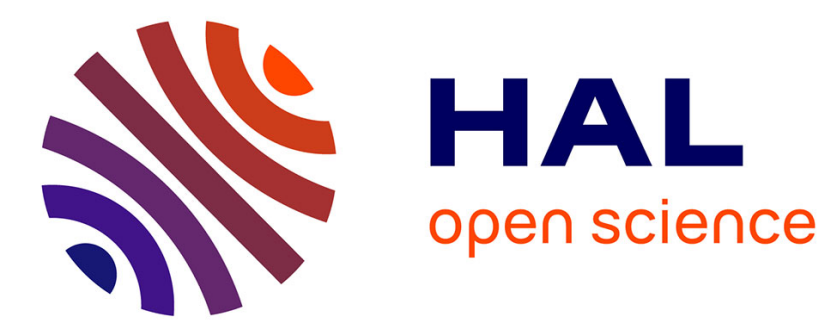

\title{
In-line metallurgical process control in the steel industry
}

M. Wanin

\section{To cite this version:}

M. Wanin. In-line metallurgical process control in the steel industry. Journal de Physique IV Proceedings, 1993, 03 (C7), pp.C7-1101-C7-1107. 10.1051/jp4:19937172 . jpa-00251803

\section{HAL Id: jpa-00251803 https://hal.science/jpa-00251803}

Submitted on 1 Jan 1993

HAL is a multi-disciplinary open access archive for the deposit and dissemination of scientific research documents, whether they are published or not. The documents may come from teaching and research institutions in France or abroad, or from public or private research centers.
L'archive ouverte pluridisciplinaire HAL, est destinée au dépôt et à la diffusion de documents scientifiques de niveau recherche, publiés ou non, émanant des établissements d'enseignement et de recherche français ou étrangers, des laboratoires publics ou privés. 


\title{
In-line metallurgical process control in the steel industry
}

\author{
M. WANIN
}

IRSID Saint-Germain-en-Laye, France

\section{IN-LINE METALLURGICAL PROCESS CONTROL IN THE STEEL INDUSTRY}

\author{
Maurice WANIN
}

IRSID Saint-Germain-en-Laye

\section{ABSTRACT}

The steel products manufacturing involves a long line of complex processes: liquid metal elaboration, solidification, hot and cold transformation by rolling surface protection by coating. The Process Control aims at improving global productivity and quality of the resulting products by optimizing each elementary process as well as management of tools or workshops interfaces. Complex processes, involving generally many variables, require for their control more or less sophisticated models. These process models are either analytical when physical and thermodynamical mechanisms are known or statistical or knowledge based, according to circumstances. In any case, it is necessary to have a reliable and precise instrumentation to adjust undetermined parameters during model development and to be able to take into account external parameters variability during current wotking. This instrumentation concerns both running of machines and testing of manufactured materials under harsh environment conditions of Iron and Steel industry: temperature, dusts, steam, electromagnetic interferences, vibrations, ... . In this context, in-line Non Destructive Testing methods contribute efficienly because they may give directly and in real time products characteristics, integrating both drifts of machines and sensors due to their ageing and the abnormal spread of material entering the process. These methods induce the development of sophisticated inspection equipments whose strategic significance is such that their failure to operate can require production shutdown. The paper gives some representative examples of improvement of the accuracy of an in-line measurement or controlling of elementary processes or processes interfaces: temperature measurement by infrared pyrometry, thickness profile determination by X-ray array sensor, recrystallization control in continuous by $X$-ray and ultrasonic methods, automatic detection and indentification of surface defects by optics, cracks detection on as-cast hot slabs by eddy currents. 


\section{OBJECTIVES AND MEANS OF PROCESS CONTROL}

The manufacturing sequence for steel products present itself as a long line of complex processes. For instance, the manufacturing of flat coated products involve many operations starting from the ore and coal: pyrometallurgy in coking and sinter plants, elaboration of liquid metal in blast-furnace and converter, solidification in continuous casting installation, hot transformation in hot roll-mill, cold transformation in pickling line, cold roll-mill, annealing installation and skin-pass, electrochemistry and organic chemistry in various coating lines. These different processes operate in a more or less continuous manner and have strong interactions between them. They are conditioned by multiple parameters and frequent transients. The response inertia to a command varies from one millisecond for a roll mill to one day for a blast-furnace.

The objectives of Process Control consist in manufacturing products which present no unidentified defect, as well as homogeneous use characteristics, in compliance with precise customer specifications, at best possible cost and within the required time. These objectives can only be met by optimizing the control of each of the elementary processes which make up the long manufacturing line of steel, as well as the management of tools and workshops interface, each tool or workshop placing itself generally as the customer of the preceding tool or process and the supplier of the following one.

As regards methodology, Process Control comprises two complementary aspects: the "Direct Measurement" aspect and the "Modelizing" one. It is obvious that a simple process can be controlled by means of a regulation loop in which direct measurement plays an essential part (Fig 1).

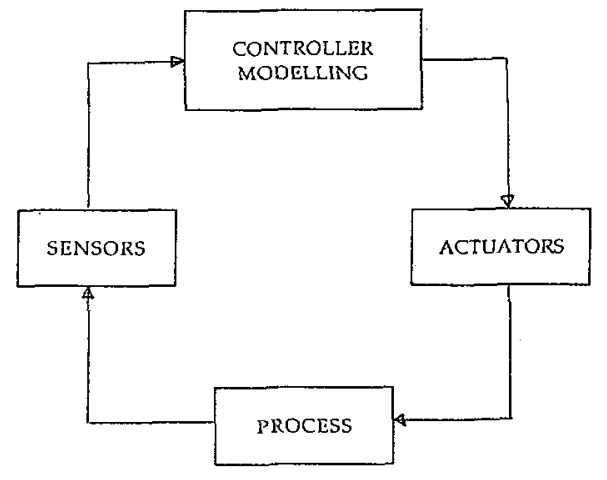

Figure 1 : Automatisation principle.

As the process becomes complex, involving multiple variables, an action and anticipation strategy is required. The corresponding algorithms must be based on the most faithful possible modelizing of the physico-chemical or thermo-mechanical mechanisms implemented in the process. As a matter of fact, complexity is such that the only available tool will be either a semi-physical approximate model, a model based on the statistical analysis of the process data around an operating point or even a knowledge based model. Whatever their sophistication level, these models include a certain number of undetermined factors which need readjusting by measurements on the site. Moreover, in spite of the power of the current computers and the quality of the models and their settings, experience demonstrates that it is always useful and in certain cases essential to obtain a measured value, preferably to a computed one.

A good long known illustration of this point is given by the evolution of steel refining control in the oxygen converter. This process consists in refining the pig iron coming from the blast furnace by blowing pure oxygen with a lance located above the bath and with nozzles set up in the bottom of the vessel. Theorically, the process may be controlled from the initial analysis of entering materials, oxygen flowrates and analysis of gaz. The development of the sublance method, a method which permits the measurement of the temperature and the sampling of a specimen for analysis during blowing operation, enables an outstanding reduction by direct in-process measurements of the final temperature and composition spread, while maintaining a correct productivity level. 
Enhancements in the field of Process Control are therefore dependant on evolution in complementary and non competing topics: Instrumentation and Non Destructive Testing on the one hand, Modelizing on the other hand.

\section{CONTRIBUTION OF INSTRUMENTATION AND NON DESTRUCTIVE TESTING IN PROCESS CONTROL}

Two types of needs are to be distinguished: Instrumentation required for the setting of the modelsInstrumentation being temporary by nature and therefore accepting a less hardened degree but at the opposite requiring flexibility and adaptability to an extended measurement range- and Instrumentation for the routine control for which hardiness, reliability and maintainability are required. The needs to take into account both the drift of the manufacturing tools and sensors due to their ageing, and the fact that the incoming products present characteristics that are not always well known and homogeneous, lead to complement the measurement on tools which remains an essential step, by a continuous non destructive measurement on the products. This latter measurement often results in the installation, at the end of each process, of a generally sophisticated inspection equipment whose strategic significance is such that its failure to operate can require production shutdown.

This measurement must obviously be performed in the generally harsh environment conditions of the steel industry: temperature, dusts, steam, vibrations, electromagnetic interferences, ..., together with sometimes high moving velocities: 1 to $4 \mathrm{~m} / \mathrm{mn}$ in continuous casting, 15 to $20 \mathrm{~m} / \mathrm{s}$ in flat products rolling mills, up to $80 \mathrm{~m} / \mathrm{s}$ in wire drawing train. These determinations must be made in a context of reducing allowable defect size and narrowing tolerances in composition, dimensions and mechanical properties. Typically, the size of inclusions or inclusions clusters to be detected is currently of $20 \mathrm{um}$ in construction steels for parts submitted to fatigue loading, $10 \mathrm{um}$ in steel for packing. The size of slivers in stainless steel are $0.01 \mathrm{~mm}$ wide and $1 \mathrm{~mm}$ long, cracks on as-cast billets for higher range wire are 0.3 $\mathrm{mm}$ deep and $10 \mathrm{~mm}$ long. The edge thinning for silicon steel sheets for transformer must be smaller than $0.1 \%$ of the nominal value, the accuracy on hardness determination must be plus or minus $10 \mathrm{Hv} 5$. All these requirements involve the real time acquisition and digital processing of high data flows with equipments which must be well dimensioned mechanically.

In the field of tool and process instrumentation, the required actions may be grouped around various subjects:

- Measurement of physical values: electrical, magnetic, mechanical, geometric, thermal, ...

- Measurement adapted to Process Engineering: in-line analysis, specially gas analysis, flowrates, ...

- Tool condition diagnosis by vibratory analysis and Non Destructive Testing technologies.

- Characterization of the radiative properties of surfaces, namely the definition of the emissivity factor, with a view to application to temperature measurement of the products by infrared pyrometry.

- Visualizing of rapid phenomena.

In the field of product inspection, the main subjects are the following:

- Dimensional check, including the definition of global 3D shapes, characterization of flatness, thickness of the metallic or organic coatings.

- Non DestructiveDetection of surface and internal defects.

- Non Destructive characterization of surface conditions (aspect, roughness, surface cleanliness, ... ) and of metallurgical conditions ( recrystallization, texture, hardness, grain size measurement, ...) .

In addition to the above properly said measurement steps, it is obviously necessary to develop the activities concerning signal processing, which are essential to make the best use of the data delivered by the sensors located on the installations, as well as those pertaining to industrial networks and information systems required for checking proper operation of all sensors distributed on the tools, and transferring of the data to the procees computer and to actuators. 


\section{SOME APPLICATIONS OF INSTRUMENTATION AND NON DESTRUCTIVE METHODS IN PROCESS CONTROL}

The following examples are representative of the works performed by different measurement teams in steel and other material industry, either to improve the accuracy of in-line measurement (this is an essential element for the on site application of the new processes developed in the laboratory and in-line with the correct handling of transients ), or to control an elementary process, or finally to handle the interface between tools and workshops, aiming at the global optimization of the complete manufacturing channel.

\subsection{Temperature measurement by infrared pyrometry}

The continuous temperature measurement of moving products is generally carried out by infrared pyrometry. One of the essential factors to obtain an accurate and exact value of this temperature consists in knowing the exact emissivity factor of the product surface in the measurement conditions and specially during the transients, for instance during the coil changing in the continuous annealing process. It was necessary to develop a specific equipment for this purpose (Fig 2), comprising a sphere-furnace in which the real processing conditions (atmosphere, temperature cycle) can be simulated on steel samples whose surface conditions ( roughness, surface cleanliness ) correspond to those of the steel actually found in practice.

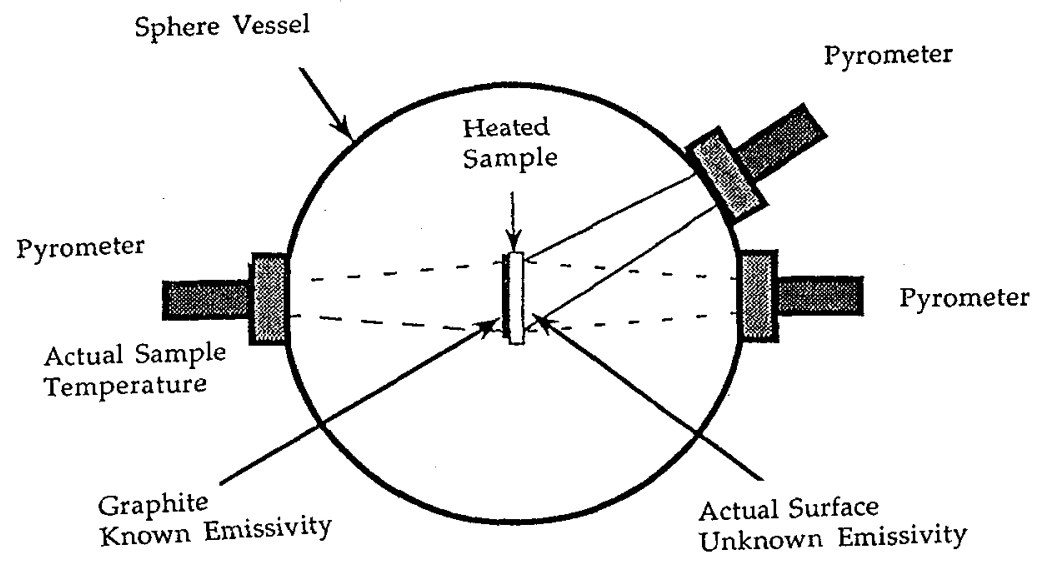

Figure 2 : Emissivity factor determination

The emissivity factor is calculated by comparison between a measurement taken on the actual surface and another taken on a reference surface of known emissivity. The choice of optimum wave lengths to be selected for the final pyrometer to use in order to minimize the effects of material emissivity variations during the process and notably during the transients, is made based on an analysis performed with a spectroradiometer. Thanks to these actions, it can be assumed that the actual temperature of the product after taking a certain number of steps at the time of implementation in the industrial installation is known to within $10 \mathrm{C}$. Such an accuracy level is required to ensure the repeatibility of the final characteristics of the product.

\subsection{Thickness profile measurement by $\mathrm{X}$-ray gauge on cold rolling mill}

The customer specifications as regards thickness variability on cold rolled sheets are for certain products in the order of a few thousandths of nominal value over the whole sheet width. These tolerances are to be observed notably near the edges. It is possible to act on the adjustment of the last rolling mill stands ( shiftable rolls ) to reduce edge thickness thinning, but to control these actuators, it is necessary to have accurate enough measurement means to be coupled with the process. The lateral resolution near the edges must be $1 \mathrm{~mm}$. An equipment (Fig 3), based on the conventional X-ray absorption principle and using an X-ray sensitive array sensor had to be developed for this application. Development work involved adaptation of the standard sensor,previously built for industrial radiography, to the strict metrology requirements, as well toughening of the complete device to the severe environment of the 
rolling mill. All the required performance levels - a few thousandths of nominal thickness value every 2 $\mathrm{mm}$ in width- were reached.

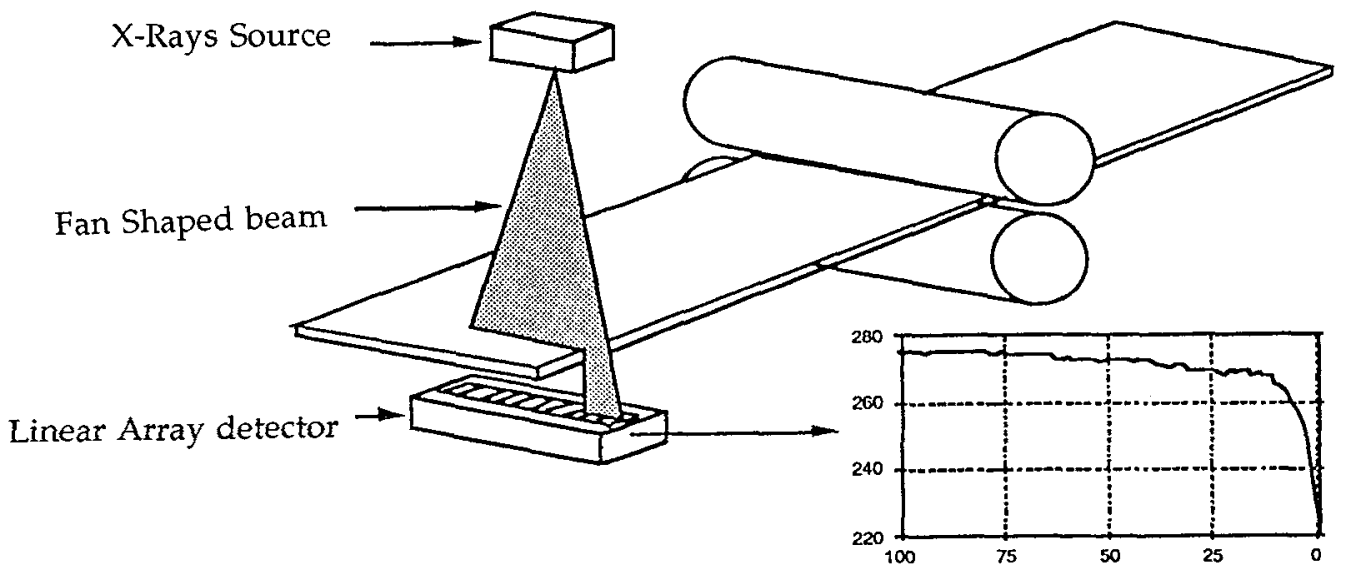

Figure 3: Thickness profile measurement of cold rolled strip with a linear array X-Rays detector.

\subsection{Recrystallization control in continuous annealing process}

The correct recrystallization control of the strip going out the continuous annealing following the cold rolling operation involves the homogeneity and the level of mechanical properties (hardness, grain size, texture anisotropy, ... ) and therefore use properties ( drawability, ... ) of final product. Equipments have been developed to evaluate in line the homogeneity and the level of texture anisotropy. These methods are based either on ultrasonic waves propagation velocities in three directions (rolling direction, transverse direction and 45 degrees direction) or on X-ray diffraction (Fig 4). Thanks these technics, it is possible to calculate the Crystallographic Orientation Distribution Function at order 4 and by application of a mechanical model to calculate $\bar{r}( \pm 0.1)$ and $\Delta r( \pm 0.2)$ coefficients.

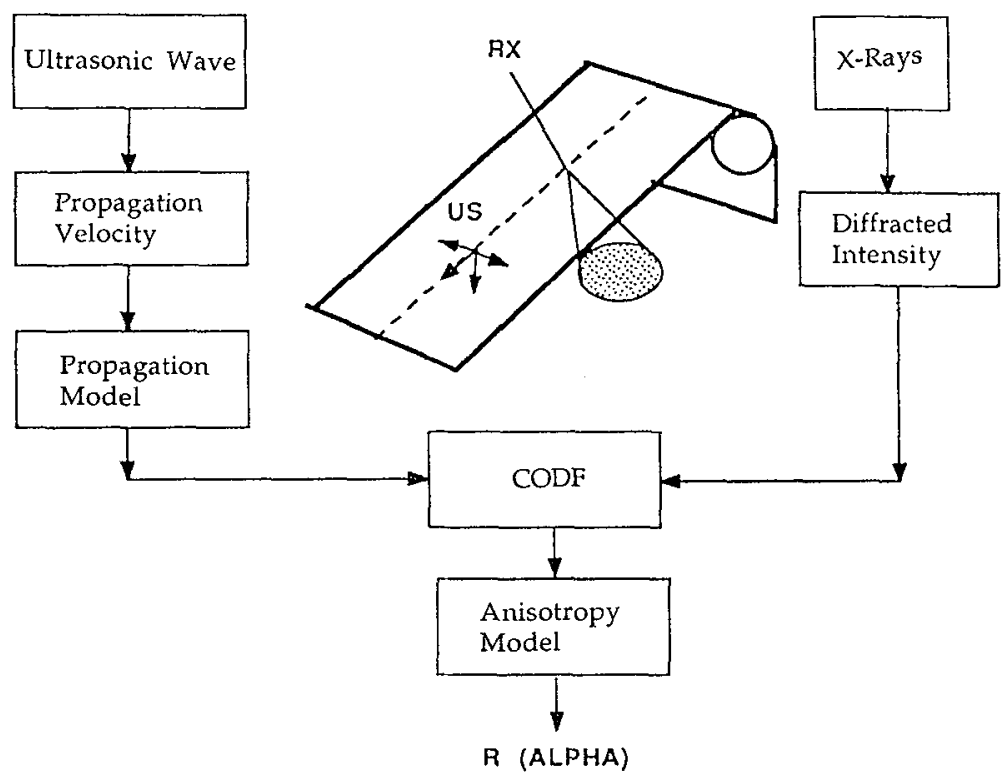

Figure $4:$ In-line texture characterization by Ultrasonic and X-rayx methods. 


\subsection{Surface defects detection on pickled strips}

For global productivity reasons, certain processes are linked. This the case with the coupling between a hot rolled strips pickling line and a cold rolling mill, an accumulator enabling the storage of approximatively $2 \mathrm{mn}$ of production between the two processes. It is obvious that such coupling can be only achieved in good conditions that if no severe defects such as folds, large flaws, edge cracks, ..., able to cause either strip breakage or damage to work rolls, enter into the rolling mill, hence the need for a reliable detection mean for such defects at the rolling speed (i.e $10 \mathrm{~m} / \mathrm{s}$ ). An equipment was developed based on image acquisition using high resolution CCD linear cameras and suitable lighting ( Fig 5 ). The digital real time image processing with filters matched to the shape of the defects and the texture of the surface permits to present the processed image of the defect to the rolling mill controller for validation. This controller disposes of a maximum time of $2 \mathrm{mn}$ to decide either to reduce the rolling mill speed, to withdraw the rolls or to let go. Investigations on defect characteristics extraction and classification algorithms using knowledge based technology, implementing expert questioning, are now in progress with a view to the automation of the validation phase currently carried out by the controller.

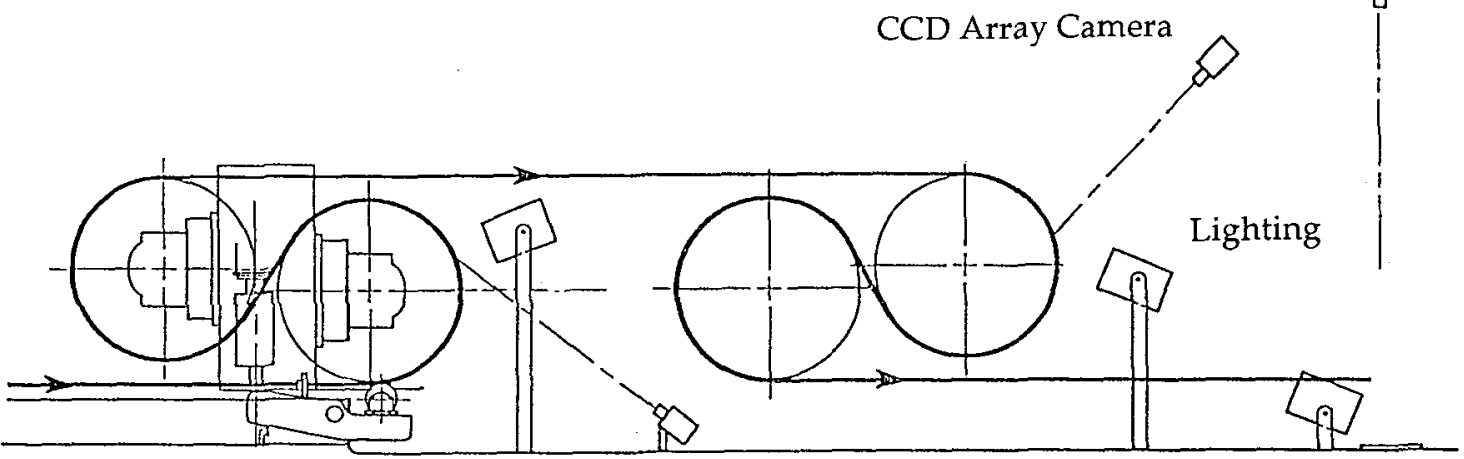

Lower Surface Inspection

Upper Surface Inspection

Figure 5: Optical surface inspection of pickled steel strips.

\subsection{Surface defects detection on as-cast slabs}

In order to improve the interface between continuous casting and rolling mill units, particularly to reduce total manufacturing time and slab stocks volume in one hand, to save a part of reheating energy on the other hand, as-cast hot slabs are more and more sent directly to hot rolling mill. This operation is only possible if all severe defects as longitudinal and transversal cracks, notably those located near angles, are correctly detected and repaired. Equipments based on eddy current method had been developed in different countries for this application. An device had been built by SOLLAC Fos and IRSID: it involves specific heads to inspect angles and small sides of the slab in one hand, a scanning head for the large sides on the other hand( Fig 6 ). Cracks detection limits on hot slabs are $1 \mathrm{~mm}$ in depth, 10 and $50 \mathrm{~mm}$ in length respectively for transverse and longitudinal defects. The sensors design and the signal processing permitted to reduce strongly the influence of oscillation marks. 


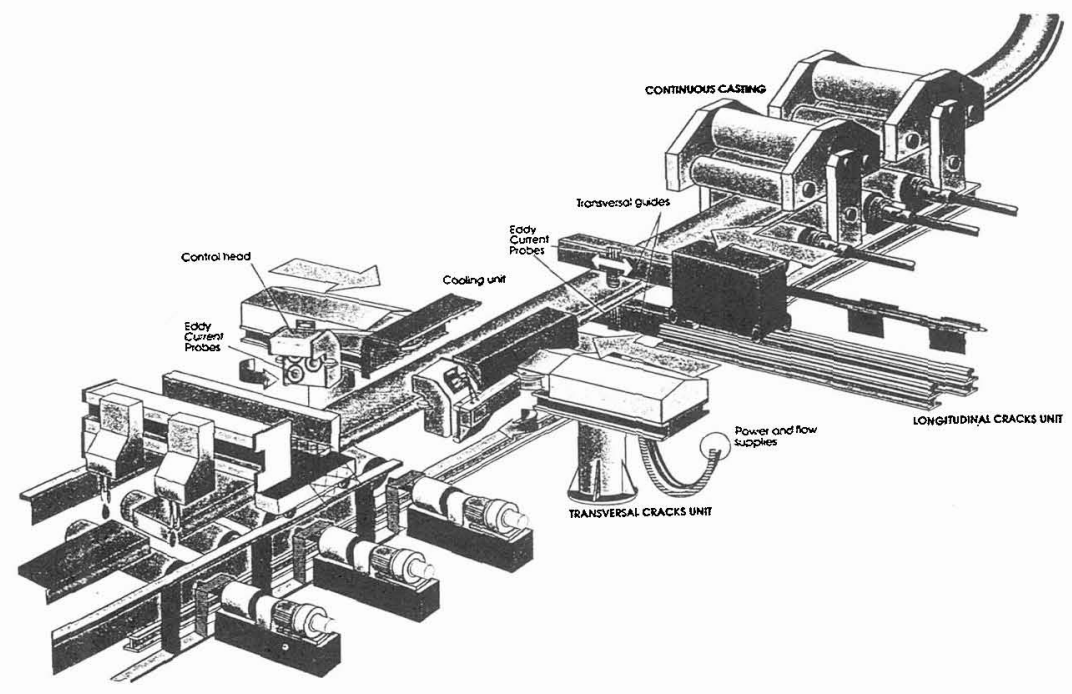

Figure $6:$ Surface defects detection on as-cast hot slabs by eddy currents.

\section{CONCLUSIONS}

The steel products manufacturing involves a long line of complex processes. The objectives of Process Control are to improve global productivity and quality of the resulting products by optimizing each elementary process as well as management of tools or workshops interfaces. As regards of methodology, Process Control comprises two essential and complementary aspects: In-line measurement and Modelizing. But best sophisticated models required reliable and precise in-line instrumentation to be correctly adjusted during their development step and to be able to take into account external parameters variability during the current work. In this context, in-line Non Destructive Testing methods contribute efficiently because they may give directly and in real time product characteristics, integrating at once drifts of machines and sensors due to their ageing and the normal spread of materials entering the process. So these methods become an essential element in the Quality Insurance more and more often required by customers. 